\title{
Non-Leishmania Parasite in Fatal Visceral Leishmaniasis-Like Disease, Brazil
}

\author{
Sandra R. Maruyama, ${ }^{1}$ Alynne K.M. de Santana, ${ }^{1,2}$ \\ Nayore T. Takamiya, Talita Y. Takahashi, \\ Luana A. Rogerio, Caio A.B. Oliveira, \\ Cristiane M. Milanezi, Viviane A. Trombela, \\ Angela K. Cruz, Amélia R. Jesus, \\ Aline S. Barreto, Angela M. da Silva, \\ Roque P. Almeida, ${ }^{3}$ José M. Ribeiro, ${ }^{3}$ João S. Silva ${ }^{3}$
}

Through whole-genome sequencing analysis, we identified non-Leishmania parasites isolated from a man with a fatal visceral leishmaniasis-like illness in Brazil. The parasites infected mice and reproduced the patient's clinical manifestations. Molecular epidemiologic studies are needed to ascertain whether a new infectious disease is emerging that can be confused with leishmaniasis.

$\mathrm{L}$ eishmaniases are caused by $\approx 20$ Leishmania species transmitted to humans through sand-fly bites and have been classified into 3 main forms: cutaneous leishmaniasis, mucocutaneous or mucosal leishmaniasis, and visceral leishmaniasis (VL; also known as kala-azar) $(1,2)$. VL is the most severe form of the disease and can be fatal if misdiagnosed or untreated (3). Cases of VL in Brazil account for $>90 \%$ of annual reported cases in Latin America (4), where the causative species is $L$. infantum.

Since 1980, sporadic co-infections of Leishmania with apparently monoxenous trypanosomatids have been described (Kaufer et al. [5]); these reports are sometimes associated with immunocompromised hosts. More recently, co-infections with Crithidia-like (6) or Leptomonas-like (7) parasites have been reported. Whether these co-infections are occasional findings or are evidence for new parasites with the potential to threaten public health remains uncertain. To investigate this problem, we

Author affiliations: Universidade Federal de São Carlos, São Carlos, Brazil (S.R. Maruyama, N.T. Takamiya, T.Y. Takahashi, L.A. Rogerio, C.A.B. Oliveira); Universidade Federal de Sergipe, Aracaju, Brazil (A.K.M. de Santana, A.R. Jesus, A.S. Barreto, A.M. da Silva, R.P. Almeida); Universidade de São Paulo, Ribeirão Preto, Brazil (C.M. Milanezi, V.A. Trombela, A.K. Cruz); National Institutes of Health, Rockville, Maryland, USA (J.M. Ribeiro); Fundação Oswaldo Cruz Bi-institucional, Ribeirão Preto Brazil (J.S. Silva)

DOI: https://doi.org/10.3201/eid2511.181548 performed whole-genome sequencing of 2 clinical isolates from a patient with a fatal illness with clinical characteristics similar to those of VL.

\section{The Study}

During 2011-2012, we characterized 2 parasite strains, LVH60 and LVH60a, isolated from an HIV-negative man when he was 64 years old and 65 years old (Table; Appendix, https:// wwwnc.cdc.gov/EID/article/25/11/18-1548-App1.pdf). Treatment-refractory VL-like disease developed in the man; signs and symptoms consisted of weight loss, fever, anemia, low leukocyte and platelet counts, and severe liver and spleen enlargements. VL was confirmed by light microscopic examination of amastigotes in bone marrow aspirates and promastigotes in culture upon parasite isolation and by positive rK39 serologic test results. Three courses of liposomal amphotericin $\mathrm{B}$ resulted in no response. At the third hospital admission, the illness resembled diffuse cutaneous leishmaniasis, in which several disseminated papular skin lesions were observed (Appendix Figure 1, panel A), and a skin biopsy revealed macrophages filled with amastigotes (Appendix Figure 1, panel B), which his liver biopsy results also showed (Appendix Figure 1, panel C). During this third admission, the LVH60a strain was isolated from the skin. Dermal lesions known as post-kalaazar dermal leishmaniasis (PKDL) have rarely been reported in Brazil (13), and the clinical aspect of the disseminated papular skin lesions on this patient differed from the clinical presentation of PKDL. Because his illness did not respond to therapy, the patient underwent splenectomy. He died of disease and surgical complications.

We used cryopreserved parasite stocks isolated from bone marrow (LVH60) and skin lesions (LVH60a) to obtain promastigotes for DNA isolation. We obtained clonal colonies and analyzed them to confirm the homogeneity of parasite cultures. For species identification, we amplified the small subunit rRNA (SSU rRNA), ribosomal internal transcribed spacer 1 (ITS1) regions, and glyceraldehyde 3-phosphate dehydrogenase gene (GAPDH) by PCR, sequenced them, and analyzed them. We used a laboratory reference L. infantum strain (HU-UFS14) used in

\footnotetext{
${ }^{1}$ These authors contributed equally to this article.

${ }^{2}$ Current affiliation: Universidade de São Paulo, Ribeirão Preto, Brazil.

${ }^{3}$ These senior authors contributed equally to this article.
} 
Visceral Leishmaniasis-Like Disease, Brazil

Table. Non-Leishmania parasites isolated from 2 patients with visceral leishmaniasis-like illness used for whole-genome sequencing, Brazil $^{*}$

\begin{tabular}{|c|c|c|c|c|c|c|c|c|c|}
\hline $\begin{array}{l}\text { Clinical } \\
\text { isolate }\end{array}$ & $\begin{array}{c}\text { Year } \\
\text { isolated }\end{array}$ & $\begin{array}{l}\text { Tissue } \\
\text { source }\end{array}$ & $\begin{array}{l}\text { Patient } \\
\text { age, y/sex }\end{array}$ & Treatment & Recidivism & $\begin{array}{l}\text { Healing } \\
\text { time }\end{array}$ & $\begin{array}{c}\text { Serologic } \\
\text { test result } \\
\text { (rK39) }\end{array}$ & MLEE & $\begin{array}{l}\text { Experimental } \\
\text { assays }\end{array}$ \\
\hline LVH60 & 2011 & BM & $64 / M$ & $\begin{array}{c}\text { Liposomal } \\
\text { amphotericin B }\end{array}$ & Yes, 3 & $\begin{array}{l}\text { Fatal } \\
\text { case }\end{array}$ & Positive & Inconclusive & $\begin{array}{l}\text { Mouse infection } \\
\text { (this study) }\end{array}$ \\
\hline $\begin{array}{l}\text { LVH60a } \\
\text { (DPSLs) }\end{array}$ & 2012 & SL & $65 / \mathrm{M}$ & $\begin{array}{c}\text { Liposomal } \\
\text { amphotericin B }\end{array}$ & Yes, 3 & $\begin{array}{l}\text { Fatal } \\
\text { case }\end{array}$ & Positive & Inconclusive & $\begin{array}{l}\text { Mouse infection } \\
\text { (this study) }\end{array}$ \\
\hline HU-UFS14 & 2009 & BM & $15 / M$ & $\begin{array}{c}\text { Antimony, } \\
\text { amphotericin B }\end{array}$ & NA & NA & Positive & L. infantum & $\begin{array}{c}\text { NO- and } \\
\text { antimony- } \\
\text { resistant (8); } \\
\text { murine model of } \\
\text { infection (9-12). }\end{array}$ \\
\hline
\end{tabular}

experimental infections elsewhere (9-12) as control. A PCR using primers for HSP70 gene (specific to discriminate Leishmania species [14]) resulted in no amplification. Amplicon sequence analyses of SSU rRNA, ITS1, and GAPDH revealed that the LVH60 and LVH60a strains are more closely related to Crithidia fasciculata than to Leishmania. Only the HU-UFS14 clustered within the Leishmania group on a branch composed of $L$. infantum and $L$. donovani.

To characterize the organisms LVH60 and LVH60a, we determined their complete genome sequences with $>400 \times$ coverage (BioProject accession no. PRJNA398352; related accession numbers in Appendix, Tables 7,9). We assembled the reads into $\approx 4,500$ scaffolds. More than 9,000 coding sequences were deduced per isolate. Only HU-UFS14 presented a predicted haploid genome size similar to that of a known Leishmania species $(\approx 33 \mathrm{Mb})$.

To ascertain the phylogenetic relationships between these isolates, we developed a comprehensive strategy to compare all available trypanosomatid orthologous proteins, in which we calculated a pairwise distance matrix based on the median distance of orthologous genes found using the RSD algorithm (S.R. Maruyama et al., unpub. data). We identified an average of 6,093 orthologs for all considered pairs. Corroborating the phylogenies of single sequences (SSU rRNA, ITS1, and GAPDH), both clinical isolates (except HU-UFS14) clustered apart from the Leishmania clade (Figure 1), fitting into another Leishmaniinae subfamily group composed of the monoxenous genera Leptomonas, Lotmaria, and Crithidia, which infect only insect hosts (5). These results revealed that the LVH60 and LVH60a isolates do not belong to the Leishmania genus. Instead, these isolates form a robust clade including $C$. fasciculata but excluding 2 other Crithidia and Lotmaria bee parasites.

Because LVH60 and LVH60a were more closely related to monoxenous trypanosomatids, we performed experimental intravenous infections in BALB/c mice with these non-Leishmania clinical isolates or the HU-UFS14 strain to evaluate their infectious capacity. We analyzed parasite load in the spleen and liver. We found the LVH60 and LVH60a strains in the liver, although at much lower levels than HUUFS14. However, in the spleen, we detected only LVH60 (Figure 2, panel A). Because LVH60a was isolated from the skin and both LVH60 and LVH60a were barely detected in organs, we infected BALB/c mice with these parasites through the intradermal route on the ears to evaluate their capacity to generate skin lesions and compared the results with those obtained with L. major LV29, the positive control.

Only the LVH60a strain was able to establish infection and cause ear lesions (Figure 2, panel B), as measured by parasite load (Figure 2, panel C) and ear thickness (Figure 1, panel D). The injury caused by LVH60a to the ear skin was more extensive than that resulting from the L. major LV29positive control. Thus, the phenotypes observed with experimental infection corroborate the clinical manifestations in the patient; that is, the LVH60a strain isolated from skin lesions injured the skin tissue of mice under experimental cutaneous infection. Thus, these parasite strains closely related to $C$. fasciculata can be considered a new dixenous parasite able to infect mammals, such as humans and mice.

\section{Conclusions}

Our study showed that non-Leishmania, Crithidia-related parasites were involved in an atypical manifestation similar to VL in this patient. Because few drugs exist with which to treat leishmaniasis, this identification of a new trypanosomatid strain refractory to treatment that can cause disease either as a single infection or as a co-infection with Leishmania is serious and might increase the problem of disease control. This scenario highlights the urgent need for studies of new drugs to treat this new strain. Moreover, the fact that this parasite appeared in a sister phylogenetic position to $C$. fasciculata focuses attention on potential vectors because leishmaniasis is transmitted by female sand flies, whereas C. fasciculata infects only anopheline and Culex mosquitoes. Recently, both $C$. fasciculata and L. infantum sequences were detected in phlebotomine Nyssomyia whitmani samples collected in the northern region of Brazil (15). Our findings raise concerns about the need to isolate 


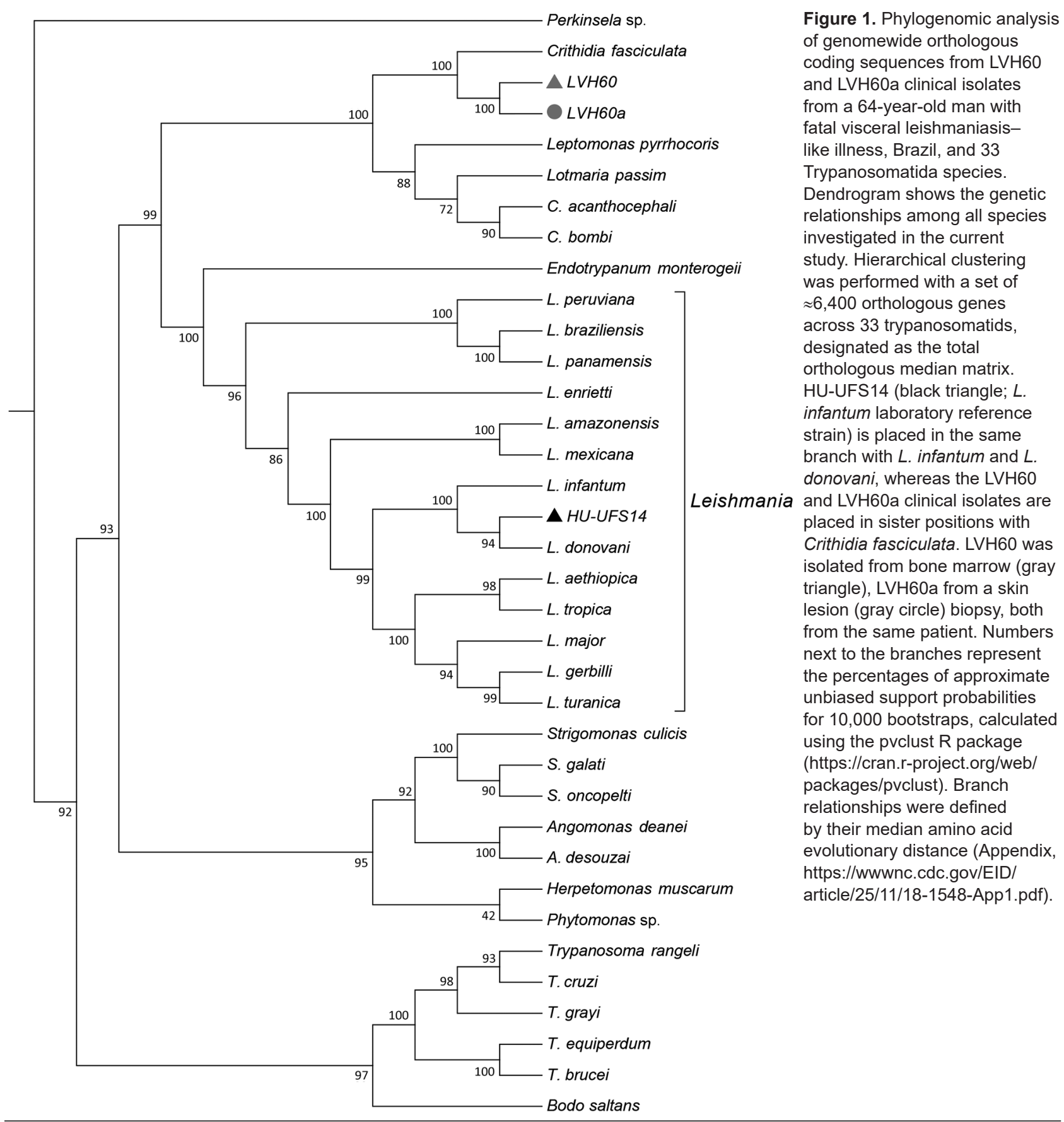

and characterize parasites from more humans, reservoirs, and vectors; map trypanosomatid distribution and epidemiologic control measures; study the sensitivity of these parasites to drugs and design new treatment options; and develop new epidemiologic/ecologic strategies to control Crithidia-related species.

\section{Acknowledgments}

We thank Iran Malavazi, Anderson Ferreira Cunha, and Felipe Roberti Teixeira for their generous and continuing support.
This work was supported by grants from the Fundação de Amparo à Pesquisa do Estado de São Paulo (FAPESP), under agreements 2016/20258-0 (Young Investigator Award to S.R.M.) and 2013/08216-2 (Center for Research in Inflammatory Diseases), and by Coordenação de Aperfeiçoamento de Pessoal de Nível Superior (CAPES) grant no. 23038.005304/2011-01 and Conselho Nacional de Desenvolvimento Científico e Tecnológico (CNPq) grant no. 552721/2011-5. J.M.R. was supported by the Intramural Research Program of the National Institute of Allergy and Infectious Diseases. S.R.M. received a 


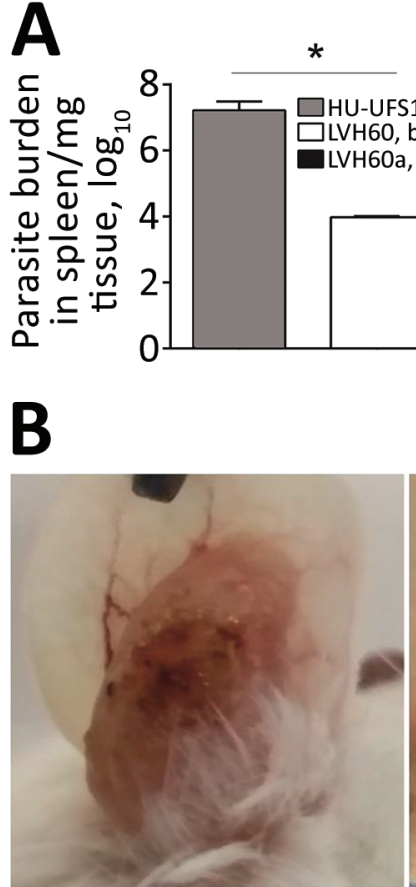

LVH6Oa
Skin isolate

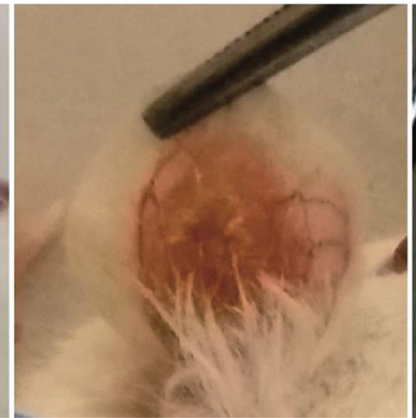

L. major

LV29
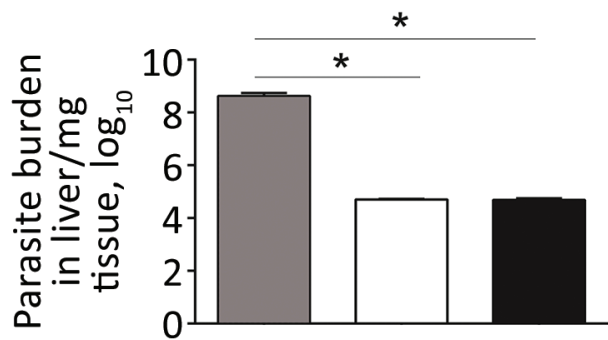

Figure 2. Experimental infection of $\mathrm{BALB} / \mathrm{c}$ mice with $\mathrm{LVH} 60$ and LVH60a clinical isolates obtained from a 64-year-old man with fatal visceral leishmaniasis-like illness, Brazil. LVH60 was isolated from bone marrow, LVH60a from a skin lesion biopsy. Female $B A L B / c$ mice were infected intravenously with $10^{7}$ stationaryphase promastigotes. After 4 weeks of infection, spleen and liver samples were collected. Parasite loads were determined by a limiting dilution assay of spleen and liver homogenates and are expressed as the mean \pm SD. A) LVH60 strain infection in mice resulted in parasite detection in the spleen and liver; the LVH60a strain was not detected in the spleen. B) For cutaneous infection, BALB/c mice were injected subcutaneously in the right ear dermis with $10^{6}$ stationary phase promastigotes. Infected ears were collected and imaged. C) Parasite burden in ears was assessed by a limiting dilution assay. D) Ear thickness was measured weekly with a digital caliper. The HU-UFS14 strain (L. infantum) was used as a positive control for experimental visceral leishmaniasis $(A)$, whereas the LV29 strain ( $L$. major) was used as a positive control for experimental cutaneous leishmaniasis. The results represent 3 independent experiments. Error bars indicate SD. ND, not detected. ${ }^{*} p<0.05$. fellowship from FAPESP (2017/16328-6). N.T.T., L.A.R., and T.Y.T. received scholarships from FAPESP (2018/05767-1, 2018/26799-9 and 2019/03095-9, respectively).

\section{About the Author \\ Dr. Maruyama is an early-career investigator based in the Department of Genetics and Evolution at Federal University of São Carlos, Brazil, as research fellow through the FAPESP Young Investigator Award agreement. Her primary research interests include understanding parasite-host interactions through comparative genomics and functional genomics. Dr. de Santana is a postdoctoral fellow in the Department of Biochemistry and Immunology, Ribeirão Preto Medical School, University of São Paulo, Brazil. Her primary research interest is in innate immunity and regulation of the immune response by intracellular pathogens.}

\section{References}

1. World Health Organization. Leishmaniasis [cited 2019 Mar 26]. http://www.who.int/leishmaniasis/en

2. Centers for Disease Control and Prevention. Parasitesleishmaniasis [cited 2019 Apr 23]. https://www.cdc.gov/parasites/ leishmaniasis

3. El Hajj R, El Hajj H, Khalifeh I. Fatal visceral leishmaniasis caused by Leishmania infantum, Lebanon. Emerg Infect Dis. 2018;24:906-7. https://doi.org/10.3201/eid2405.180019

4. Alvar J, Vélez ID, Bern C, Herrero M, Desjeux P, Cano J, et al.; WHO Leishmaniasis Control Team. Leishmaniasis worldwide and global estimates of its incidence. PLoS One. 2012;7:e35671. https://doi.org/10.1371/journal.pone.0035671

5. Kaufer A, Ellis J, Stark D, Barratt J. The evolution of trypanosomatid taxonomy. Parasit Vectors. 2017;10:287. https://doi.org/10.1186/s13071-017-2204-7

6. Ghobakhloo N, Motazedian MH, Naderi S, Ebrahimi S. Isolation of Crithidia spp. from lesions of immunocompetent patients with suspected cutaneous leishmaniasis in Iran. Trop Med Int Health. 2019;24:116-26. 
7. Ghosh S, Banerjee P, Sarkar A, Datta S, Chatterjee M. Coinfection of Leptomonas seymouri and Leishmania donovani in Indian leishmaniasis. J Clin Microbiol. 2012;50:2774-8. https://doi.org/10.1128/JCM.00966-12

8. de Azevedo AF, de Lisboa Dutra JL, Barbosa Santos ML, de Alexandria Santos D, Alves PB, de Moura TR, et al. Fatty acid profiles in Leishmania spp. isolates with natural resistance to nitric oxide and trivalent antimony. Parasitol Res. 2014;113:19-27. https://doi.org/10.1007/s00436-013-3621-y

9. Nascimento MSL, Ferreira MD, Quirino GFS, Maruyama SR, Krishnaswamy JK, Liu D, et al. NOD2-RIP2-mediated signaling helps shape adaptive immunity in visceral leishmaniasis. J Infect Dis. 2016;214:1647-57. https://doi.org/10.1093/infdis/jiw446

10. Lima MHF, Sacramento LA, Quirino GFS, Ferreira MD, Benevides L, Santana AKM, et al. Leishmania infantum parasites subvert the host inflammatory response through the adenosine A2 receptor to promote the establishment of infection. Front Immunol. 2017;8:815. https://doi.org/10.3389/fimmu.2017.00815

11. Nascimento MS, Carregaro V, Lima-Júnior DS, Costa DL, Ryffel B, Duthie MS, et al. Interleukin 17A acts synergistically with interferon $\gamma$ to promote protection against Leishmania infantum infection. J Infect Dis. 2015;211:1015-26. https://doi.org/10.1093/ infdis/jiu531

12. Sacramento LA, da Costa JL, de Lima MH, Sampaio PA, Almeida RP, Cunha FQ, et al. Toll-like receptor 2 is required for inflammatory process development during Leishmania infantum infection. Front Microbiol. 2017;8:262. https://doi.org/10.3389/ fmicb.2017.00262

13. Carnaúba D Jr, Konishi CT, Petri V, Martinez ICP, Shimizu L, Pereira-Chioccola VL. Atypical disseminated leishmaniasis similar to post-kala-azar dermal leishmaniasis in a Brazilian AIDS patient infected with Leishmania (Leishmania) infantum chagasi: a case report. Int J Infect Dis. 2009;13:e504-7. https://doi.org/10.1016/ j.ijid.2009.01.022

14. Espada CR, Ortiz PA, Shaw JJ, Barral AMP, Costa JML, Uliana SRB, et al. Identification of Leishmania (Viannia) species and clinical isolates of Leishmania (Leishmania) amazonensis from Brazil using PCR-RFLP of the heat-shock protein 70 gene reveals some unexpected observations. Diagn Microbiol Infect Dis. 2018;91:312-8. https://doi.org/10.1016/j.diagmicrobio. 2018.03.004

15. Machado TDO, Minuzzi-Souza TTC, Ferreira TS, Freire LP, Timbó RV, Vital TE, et al. The role of gallery forests in maintaining Phlebotominae populations: potential Leishmania spp. vectors in the Brazilian savanna. Mem Inst Oswaldo Cruz. 2017;112:681-91. https://doi.org/10.1590/0074-02760170126

Address for correspondence: Sandra R. Maruyama, Universidade Federal de São Carlos, Departamento de Genética e Evolução, Rodovia Washington Luis km 235, 13565-905, São Carlos, SP, Brazil; email: srmaruyama@gmail.com

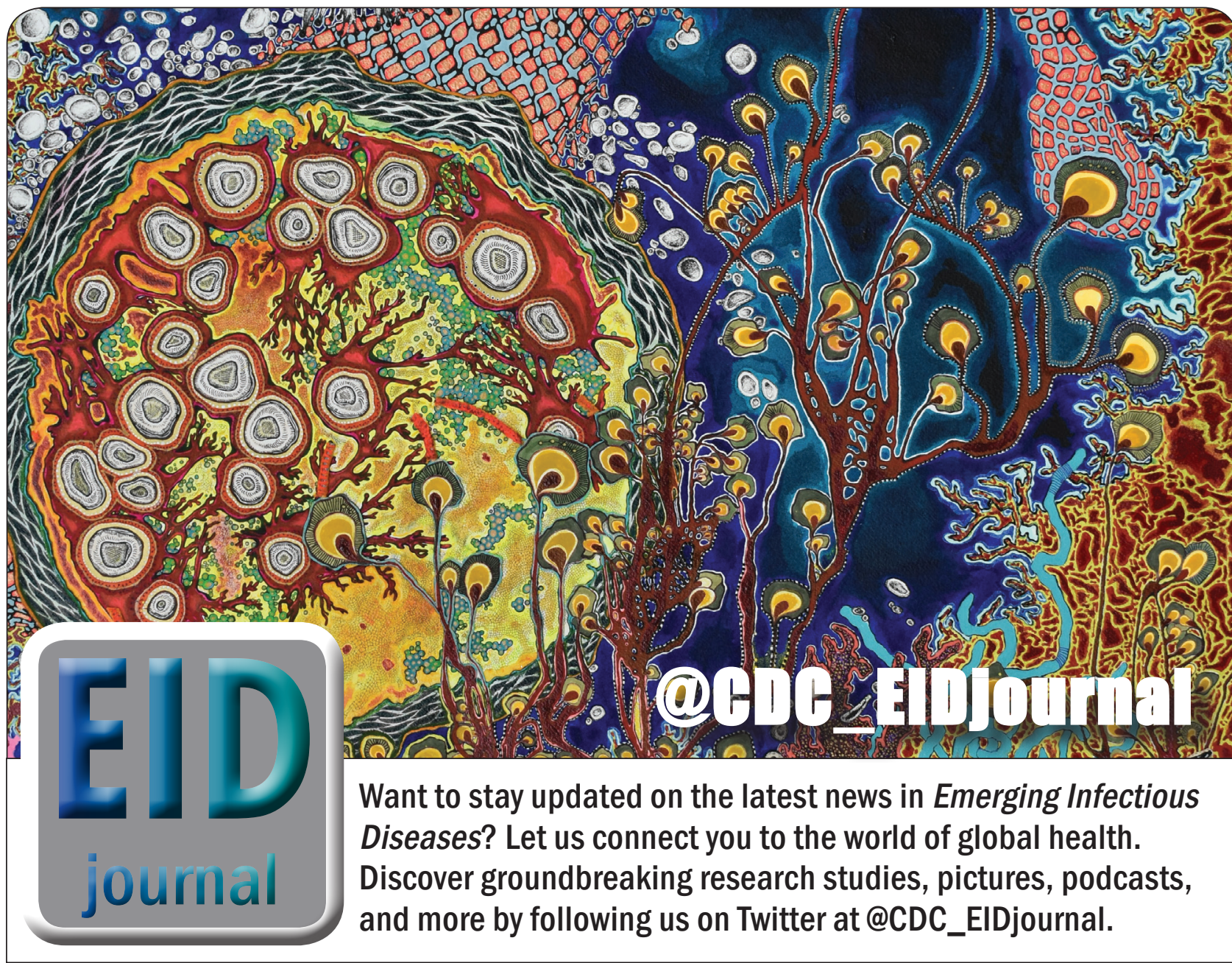

